\title{
PENERAPAN METODE CLUSTERING DENGAN ALGORITMA K-MEANS PADA PENGELOMPOKAN DATA PENGHASILAN ORANG TUA SISWA
}

\author{
Dionisius Missa, Sentot Achmadi, Ali Mahmudi \\ Program Studi Teknik Informatika S1, Fakultas Teknologi Industri \\ Institut Teknologi Nasional Malang, Jalan Raya Karanglo km 2 Malang, Indonesia \\ dionmissa1998@gmail.com
}

\begin{abstract}
ABSTRAK
Di Indonesia masih banyak siswa yang tidak mampu untuk melanjutkan pendidikan karena mahalnya biaya pendidikan. Salah satu penyebab siswa tidak melanjutkan pendidikan adalah faktor sosial dan ekonomi orang tua yang mempengaruhi. Oleh sebab itu, dari pihak sekolah tidak ingin siswanya putus sekolah karena orang tua siswa tidak mampu membayar secara lunas biaya pendidikan setiap kenaikan semester pada siswa yang tepat dan tidak salah sasaran sehingga siswa dapat menyelesaikan pendidikannya tampa terbebani dengan baiya pendidikan yang belum lunas. Dalam penetuan biasanya sering terjadi kendala dikarenakan banyak data siswa yang memyebabkan kendala dalam melakukan pengelompokan data siswa kemungkinan yang lebih besar menghasilkan kesalahan saat menentukan siswa yang sangat membutuhkan penundaan pembayaran. Untuk penelitian ini, dibangun sebuah sistem sehingga bisa menerapkan metode $K$-Means, dalam membantu sekolah untuk menentukan penggolongan data siswa yang membutuhkan penundaan pembayaran setiap pada saat kenaikan semester dengan tepat sasaran. Agar proses tersebut dapat mambantu sekoah dalam mempersingkat proses pengolahan data siswa yang banyak. Sedangkan untuk kriteria yang pakai pada sistem ada 5 yakni pekerjaan ayah, pendapatan ayah, pekerjaan ibu, pendapatan ibu dan jumlah anak. Sistem dirancang menggunakan pemrograman CodeIgniter, PHP, JavaScript dan MYSQL sebagai databese-nya. Pada proses hasil pengujian aplikasi, yang telah menggunakan metode $K$-Means untuk proses pengelompokan data siswa yang membutuhkan penundaan pembayaran dapat menghasilkan tingkat akurasi sebanyak $85 \%$. Untuk proses pengujian ini dilakukan perbandingkan data siswa lama dengan hasil perhitungan K-Means, sehingga dengan sistem tersebut diharapkan bisa membantu pihak sekolah dalam mengelompokan data siswa dengan akurat
\end{abstract}

Kata kunci : K-Means, pengelompokan data penghasilan orang tua siswa, $p h p, M y S Q L$.

\section{PENDAhUluan}

\subsection{Latar Belakang}

Pendidikan sangat berperan penting sebagai proses peningkatan sebuah kualitas sumber daya manusia dalam upaya pembangunan sebuah bangsa dan negara. Melalui sebuah proses pendidikan yang sangat bagus, dapat diperoleh berbagai hal baru sehingga bisa digunakan dalam menciptakan sumber daya manusia yang berkualitas. Di Indonesia masih banyak siswa yang tidak mampu untuk melanjutkan pendidikan karena mahalnya biaya pendidikan.

Salah satu penyebab siswa tidak melanjutkan pendidikan adalah faktor sosial dan ekonomi orang tua yang mempengaruhi. Oleh sebab itu, dari pihak sekolah tidak ingin siswanya putus sekolah karena orang tua siswa tidak mampu membayar secara lunas biaya pendidikan setiap kenaikan semester. Maka sekolah membutuhkan sebuah sistem yang dapat mengelompokkan siswanya, berdasarkan penghasilan orang tua siswa dan berbagai kriteria pertimbangan lainya. Sehingga sekolah dapat memberikan penundaan pembayaran setiap kenaikan semester, pada siswa yang tepat dan tidak salah sasaran sehingga siswa dapat menyelesaikan pendidikannya tampa terbebani dengan baiya pendidikan yang belum lunas.

Pada proses hasil survei yang dilakukan disekolah, sering ditemukan terjadi kendala untuk menetukan siswa yang menerima penundaan pembayaran. Pada permasalahan tersebut dikarenakan banyak data siswa yang memyebabkan kendala dalam melakukan pengelompokan data siswa, dimana membutuhkan waktu cukup lama dan juga terjadi kemungkinan besar menghasilkan kesalahan dalam menentukan siswa yang sangat membutuhkan penundaan pembayaran. Sehingga dapat menimbulkan permasalahan siswa tidak melanjutkan sekolah karena biaya sekolah.

Berdasarkan hasil permasalahan yang telah dijelaskan pada paragraf sebelumnya maka pada proses penelitian ini menggunakan metode K-Means, yang dapat membantu sekolah dalam menentukan golongan siswa yang membutuhkan penundaan pembayaran kenaikan semester. Dalam melakukan proses penentuan bagi golongan siswa yang menerima penundaan pembayaran, yakni berpatokan pada proses survei yang telah di lakukan disekolah kemudian dari hasil survei akan diproses menggunakan perhitungan metode $\mathrm{K}$ Means. Metode K-Means memiliki konsep 
pengelompokan berdasarkan ukuran kedekatan (kemiripan) dan kemudian menggunakan karakteristik tersebut sebagai vektor karakteristik atau centroid, sehingga Metode K-Means bisa menjadi solusi untuk pengklasifikasian karakteristik dari objek dan memiliki ketelitian yang cukup tinggi terhadap ukuran objek.

\subsection{Rumusan Masalah}

Berdasarkan permasalahan pada latar belakang, maka dibuatlah rumusan masalah sebagai berikut :

1. Bagaimana menerapkan metode K-Means Clustering pada data mining untuk pengelompokkan data penghasilan orang tua siswa?

2. Bagaimana membangun sistem yang menerapkan metode metode $K$-Means Clustering pada website?

\subsection{Batasan Masalah}

Berdasarkan peroses pembuatan aplikasi agar tidak terjadi penyimpangan, maksud dan tujuan utama penyusunan dalam skripsi ini maka perlu diberikan batasan masalah sebagai berikut :

1. Sistem ini dibangun dengan menggunakan metode $K$ Means.

2. Kriteria dalam penelitian ini yang digunakan diantaranya pekerjaan ayah, penghasilan ayah, pekerjaan ibu, penghasilan ibu dan jumlah anak.

3. Dalam sistem ini terdapat tiga kategori atau nilai $\mathrm{K}$ yang digunakan sebagai hasil dari pengelompokkan data penghasilan orang tua siswa yang terdiri dari kurang cukup, cukup dan sangat cukup.

4. Batasan pengambilan data menyesuikan dengan yang ada pada pihak sekolah..

5. Sistem ini hanya digunakan untuk pengelompokan data penghasilan orang tua siswa.

6. Aplikasi ini dibuat menggunakan pemrograman CodeIgniter, PHP, JavaScript dan MYSQL sebagai databese-nya.

7. Aplikasi yang dikembangkan berbasis website.

\subsection{Tujuan}

Adapun beberapa tujuan yang hendak dicapai dalam pembuatan skripsi ini adalah sebagai berikut:

1. Menghasilkan sistem data mining yang menerapkan metode K-Means sebagai suatu metode untuk pengelompokkan data penghasilan orang tua siswa berdasarkan data yang telah diperoleh.

2. Membangun suatu aplikasi data mining yang dapat mengelompokan data penghasilan orang tua siswa berdasarkan hasil pengambilan data yang sudah ditentukan.

\section{TINJAUAN PUSTAKA \\ 2.1 Penelitian Terkait}

Data mining merupakan proses mencari informasi menarik dalam data terpilih dengan menggunakan teknik atau metode tertentu. Teknik, metode, atau algoritma dalam data mining sangat bervariasi (Sowmya \& Suneetha, 2017). Data mining terbagi dalam beberapa task antara lain : asosiasi, klasifikasi, clustering dan sequence pattern. Clustering merupakan sebuah pengelompokan dimana metode tersebut mengidentifikasi objek yang memiliki kesamaan karakteristik tertentu, dan kemudian menggunakan karakteristik tersebut sebagai "vektor karakteristik" atau "centroid" (Chen et al., 2015).

SMK Swasta Jaya Krama beringin saat ini memiliki permasalahan dimana untuk menentukan siswa-siswi yang layak untuk mendapatkan potongan biaya administrasi sekolah dengan jumlah siswa 585 orang sehingga dibutuhkan sebuah Clustering data untuk menentukan siapa-siapa saja yang berhak mendapatkan potongan biaya administrasi sekolah (Basaran \& Günes, 2016). Dalam hal ini data mining clustering mempunyai peranan dalam mengolah dan mengelompokkan data pada siswa-siswi SMK Swasta Jaya Krama Beringin yang berhak menerima potongan biaya administrasi sekolah (Alelyani et al., 2019).

Siswa-siswi yang berhak menerima potongan biaya administrasi sekolah merupakan siswa-siswi dengan status siswa yatim piatu, siswa yatim atau piatu, siswa kurang mampu, siswa kakak beradik dan siswa berprestasi. Sehingga dibutuhkan sebuah data mining clustering (Defiyanti et al., 2017). Akan tetapi tidak sampai tahap data mining clustering saja untuk dapat menentukan hasil yang lebih akurat dibutuhkan sebuah algoritma K-Means (Zeebaree et al., 2017).

\subsection{Metode K-Means}

K-Means merupakan salah satu algoritma clustering dengan metode partisi yang berbasis titik pusat (centroid). Algoritma ini pertama kali diusulkan oleh MacQueen (1996) dan dikembangkan oleh Hartigan dan Wong tahun 1975. K-Means mempunyai kemampuan mengelompokan data dalam jumlah yang cukup besar dengan waktu komputasi yang cepat dan efesien (Irwansyah dan faisal, 2015).

Langkah-langkah perhitungan algoritma K-Means sebagai berikut (Irwansyah dan faisal, 2015) :

1. Tentukan berapa banyak cluster $\mathrm{k}$ dari dataset yang akan dibagi.

2. Tetapkan secara acak data $\mathrm{K}$ menjadi pusat awal lokasi klaster.

3. Untuk masing-masing data temukan pusat cluster terdekat dengan menggunakan rumus eucledien distance.

$D\left(x_{i}, u_{i}\right)=\sqrt{\sum_{i=1}^{n}\left(x_{i}-u_{i}\right)^{2}} \quad($ Persamaan 2.1) 
dengan demikian berarti masing-masing pusat cluster memiliki sebuah subset dari dari dataset, sehingga mewakili bagian dari dataset.

Dimana :

$\boldsymbol{x}_{\boldsymbol{i}}$ : Data kriteria

$\boldsymbol{u}_{\boldsymbol{i}}$ : Centroid

n : Jumlah data (atribut)

i : Iterasi

4. Untuk masing-masing cluster $\mathrm{k}$, temukan pusat luasan cluster dan perbarui lokasi dari masing-masing pusat cluster kenilai baru dari pusat luasan.

5. Ulangi langkah ke-3 dan ke-4 hingga data-data pada tiap cluster menjadi terpusat atau selesai.

\section{METODE PENELITIAN}

\subsection{Analisa Masalah}

Pengelompokan data penghasilan orang tua siswa yang dirancang ini berbasis website dengan menerapkan metode K-Means. Sedangkan untuk data siswa yang digunakan adalah data sekolah SMK Santo Yosep Nenuk.

Semoga dengan sistem yang telah dirancang dengan mengunakan metode K-Means, dapat membantu pihak sekolah SMK Santo Yosep Nenuk dalam menentukan golongan data siswa yang menerima penundaan pembayaran dengan mempersingkat waktu dalam proses mengolah data siswa. Dengan demikian dapat mengurangi kesalahan untuk menentukan golongan data siswa yang membutuhkan penundaan karena salah sasaran, sehingga terjadinya kesenjangan.

Pada desain sistem Pengelompokan data penghasilan orang tua siswa, maka pada proses penelitian ini menerapkan metode K-Means untuk menentukan golongan data siswa di tunjukkan pada Gambar 1.

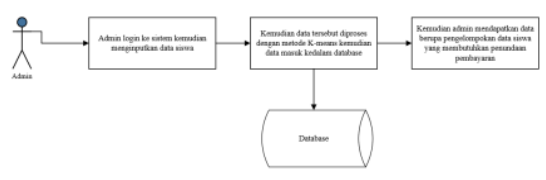

Gambar 1 Desain Diagram Sistem

Desain diagram sistem pada Gambar 1 dijelaskan proses awal dalam menjalankan aplikasi, maka Admin harus membuka sistem untuk melakukan proses login terlebih dahulu. Setelah berada didalam sistem Admin juga dapat melakukan input data siswa, dimana dari data siswa tersebut akan diproses dengan menggunakan metode $K$-Means dan akan tersimpan pada database. Kemudian akan menampilkan hasil berupa pengelompokan data siswa yang yang membutuhkan penundaan pembayaran.

\subsection{Flowchart Sistem Admin}

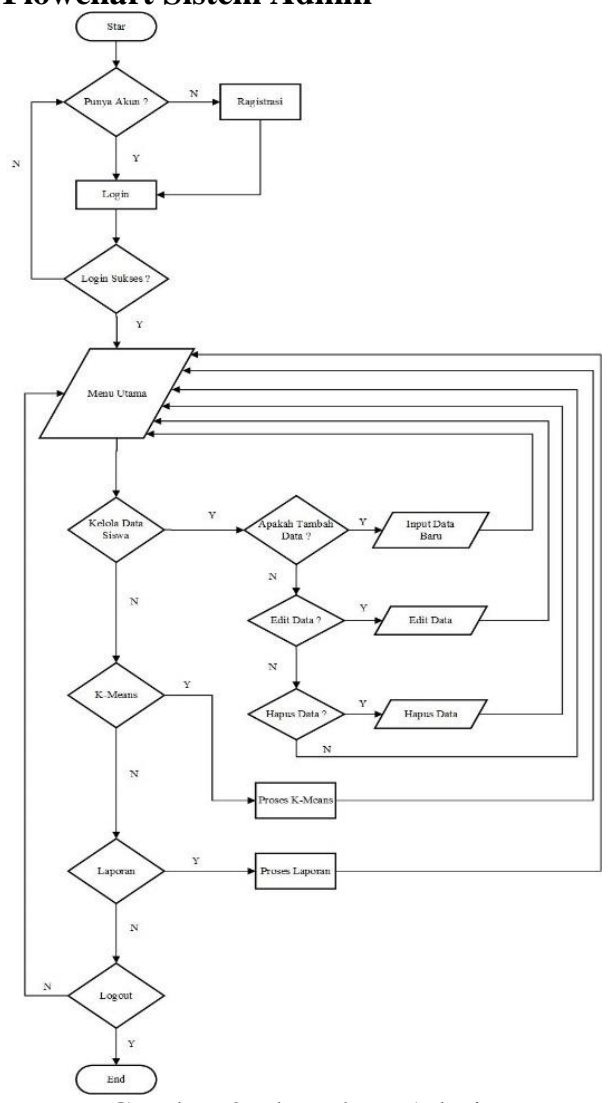

Gambar 2 Flowchart Admin

Flowchart sistem admin yang akan dibuat pada Gambar 2 menggambarkan alur system. Penjelasan flowchart system admin :

a. Login

Saat membuka system, untuk melakukan login ke system maka di lakukan registrasi untuk bisa login dan pada saat memasukan username dan password jika proses login berhasil dan sukses maka masuk pada halaman administrator.

b. Menu Utama

Pada saat melakukan login memasukan username dan password sebagai hak akses penuh admin. Apabila proses login admin berhasil dilakukan akan tampil halaman utam admin yang terdapat nama sekolah, logo sekolah serta visi misi sekolah.

c. Kelola Data Siswa

Pada halam kelola data siswa sebagai admin yang memiliki hak akses penuh dapat melakukan input, edit dan hadus data siswa berdasarkan kriteria yang sudah ada. Jika tidak maka admin akan kembali pada tampilan halaman utama.

d. K-Means

Jika data siswa yang diinputkan sudah ada dan lengkap sesuai dengan kriteria maka proses selanjutnya dilakukan perhitungan untuk mengelompokan data 
siswa tersebut dengan menerapkan metode K-Means, apabila data siswa sudah di lakukan perhitungan dan proses pengelompokan data maka data tersebut tersimpan otomatis pada menu laporan.

\section{e. Laporan}

Pada halaman menu laporan sudah terdapat daftar data siswa yang telah berhasil di lakukan pengelompokan, sesuai dengan kriteria yang di tentukan sebelumnya. Untuk halaman laporan juga disini ada fitur export to microsoft excel, yang dimana admin bisa melakukan cetak data siswa ke microsoft excel.

f. Logout

Pada pilihan menu Logout ini berfungsi bagi admin saat ingin keluar dari aplikasi yang sedang dijalankan, apabila admin berhasil keluar maka admin juga di arahkan pada halaman awal saat melakukan login.

\subsection{Flowchart Sistem User}

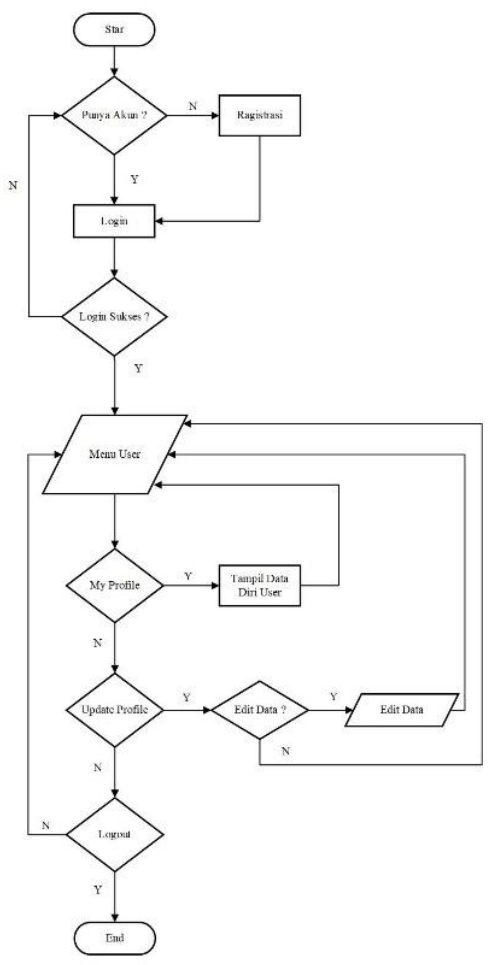

Gambar 3 Flowchart User

Flowchart sistem user yang akan dibuat pada Gambar 3 menggambarkan alur system. Penjelasan flowchart system user :

a. Login

Saat membuka system, untuk melakukan login ke system maka di lakukan registrasi, agar bisa login sebagai user maka data siswa tersebut sebelumnya sudah diinputkan oleh admin sehingga user bisa mendapatkan email dari admin yang bisa diggunakan untuk proses registrasi sehingga login. Pada saat memasukan username dan password jika proses login berhasil dan sukses maka masuk pada halaman user.

b. Menu Utama

Pada saat user melakukan login memasukan username dan password dimana hak akses penuh terdapat pada user. Apabila proses login user berhasil dilakukan akan tampil halaman utama user yang menampilkan biodata diri siswa sesuai dengan kriteria yang telah diinputkan sebelumnya oleh admin.

c. My profile

Pada my profile ini akan menampilkan data diri siswa yang telah diinputkan oleh admin pada halaman admin.

d. Update Profile

Untuk halaman update profile, siswa dapat megedit data diri apabila ada perubahan data. Tetapi siswa tidak bisa melakukan input data baru dan hapus data.

e. Logout

Pada pilihan menu Logout ini berfungsi juga bagi user saat ingin keluar dari aplikasi yang sedang dijalankan, apabila user berhasil keluar maka user juga di arahkan pada halaman awal saat melakukan login.

\subsection{Struktur Menu}

Struktur menu merupakan struktur yang menampilkan menu apa saja yang terdapat didalam aplikasi. Struktur menu yang akan dirancang di dalam aplikasi ini adalah sebagai berikut :

\section{Struktur Menu Admin}

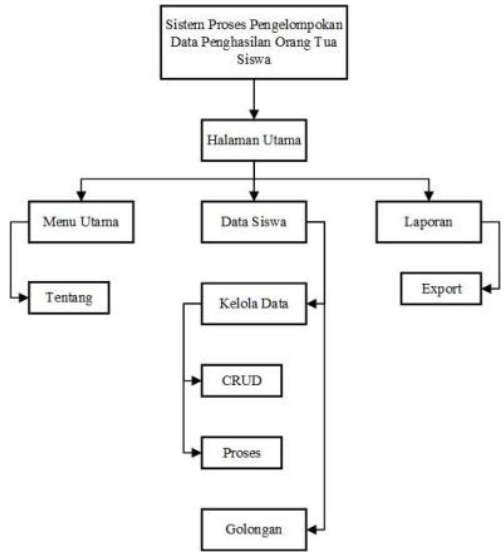

Gambar 4 Struktur Menu Admin

Pada Gambar 4 adalah alur struktur menu admin secara keseluruhan pada sistem penerapan metode clustering dengan algoritma k-means pada pengelompokan data penghasilan orang tua siswa, terdapat halaman utama admin. Pada bawah halaman admin terdapat menu utama, data siswa dan laporan. Pada menu utama terdapat logo sekolah dan visi misi dari sekolah, sedangkan pada menu data siswa terdapat menu kelola data dan golongan, pada menu kelola data admin dapat melakukan create, update, dan delete. Juga pada di bawah menu data siswa terdapat menu proses 
dimana menu tersebut berfungsi untuk proses metode $\mathrm{K}$ Means, pada menu golongan admin dapat melihat golongan data siswa yang membutuhkan penundaan pembayaran dari hasil perhitungan metode k-Means. Juga terdapat menu laporan dimana admin dapat melihat data siswa dan dapat meng-eksport data dari laporan ke microsoft excel.

\subsection{Struktur Menu User}

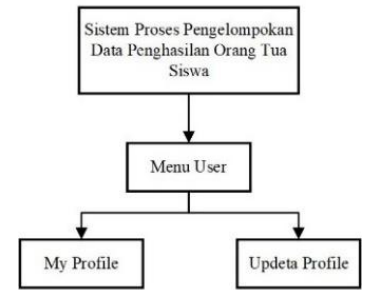

Gambar 5 Struktur Menu User

Pada Gambar 5 adalah alur struktur menu user secara keseluruhan pada sistem penerapan metode clustering dengan algoritma k-means pada pengelompokan data penghasilan orang tua siswa, terdapat menu user. Pada bawah halaman menu userterdapat my profile dan update profile. Jadi pada menu my profile akan menampilkan data diri user sedangkan pada menu update profile, user akan melakukan edit data apabila ada perubahan data.

\section{HASIL DAN PEMBAHASAN}

\subsection{Halaman Data Siswa}

Pada tampilan ini akan menampilkan data siswa yang telah di tentukan di antaranya nis, nama, email, kelas, jurusan, alamat, pekerjaan ayah, pendapatan ayah, pekerjaan ibu, pendapatan ibu dan jumlah anak. Pada halaman ini juga terdapat terdapat beberapa fitur yaitu edit dan hapus dimana fungsinya untuk, mengubah dan menghapus data siswa apabila terjadi kesalahan dalam melakukan input data siswa. Ada juga terdapat beberapa button diantaranya button input data siswa, button proses golongkan dan button proses perhitungan K-Means seperti pada gambar 6 .

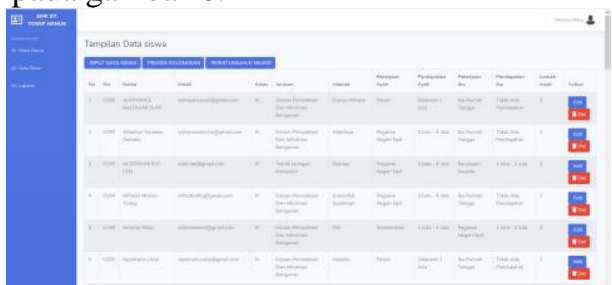

Gambar 6 Halaman Data Siswa

\subsection{Halaman Golongkan Data Siswa}

Pada tampilan golongan data siswa ini akan menampilkan hasil dari proses perhitungan dengan menugunakan metode K-Means dengan cara button perhitungan $\mathrm{k}$-means ditekan, untuk tampilan halaman golongan data siswa dapat ditunjukkan pada Gambar 7.

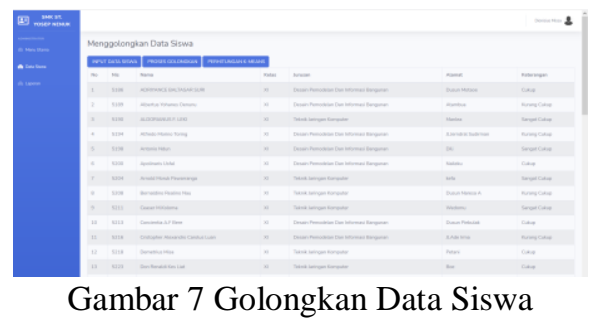

\subsection{Halaman Laporan}

Untuk halama Laporan akan menampilkan daftar tabel semua data siswa yang telah dilakukan pengelompokan atau perhitungan dengan metode $K$ Means secara lengkap, sudah terdapat siwa yang membutuhkan penundaan pembayaran. Pada tampilan Laporan ditunjukan pada Gambar 8.

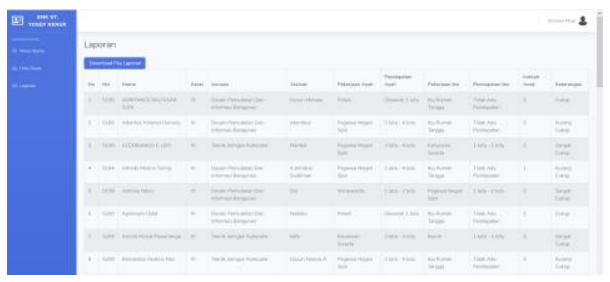

Gambar 8 Halaman Laporan

\subsection{Halaman User My Profile}

Halaman my profile menampilkan data diri siswa secara lengkap yang sudah diinputkan oleh admin. Tampilan halaman my profile seperti pada Gambar 9.

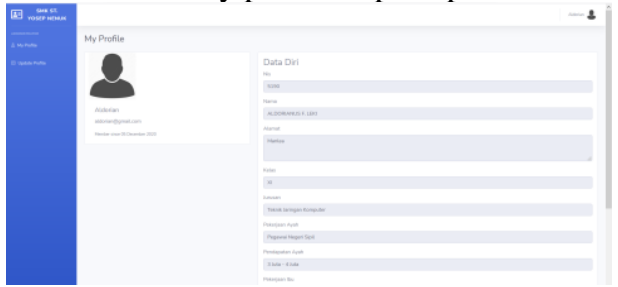

Gambar 9 Halaman My Profile

\subsection{Pengujian sistem}

Pada pengujian sistem ini adalah untuk mengetahui proses uji coba aplikasi atau sistem yang telah dibuat untuk bisa mengetahui pada setiap fungsi vital yang dijalankan, sehingga dari hasil pengujian tersebut dapat diambil kesimpulan apakah aplikasi yang dibuat dapat berjalan dengan baik dan sesuai dengan yang diinginkan pembuatan aplikasi ini pada awal. Pada pengujian aplikasi ini terdapat beberapa tahap yaitu :

\subsection{Pengujian Fungsional}

Untuk proses pengujian aplikasi ini dilakukan agar bisa mengetahui fitur yang ada pada aplikasi penerapan metode clustering dengan algoritma $k$-means pada pengelompokan data penghasilan orang tua siswa ini apakah berjalan dengan baik atau tidak. Pada hasil pengujian dapat ditunjukan pada Tabel 1. 
Tabel 1 Pengujian Fungsional

\begin{tabular}{|c|c|c|c|}
\hline No & Fungsi Yang Diuji & $\mathbf{S}$ & $\mathbf{G}$ \\
\hline 1 & Login & $\sqrt{ }$ & - \\
\hline \multirow[t]{3}{*}{2} & Halaman Data Siswa & $\sqrt{ }$ & - \\
\hline & a. Input Data Siswa & $\sqrt{ }$ & - \\
\hline & b. Edit Data Siswa & $\sqrt{ }$ & - \\
\hline \multirow[t]{4}{*}{ No } & Fungsi Yang Diuji & $\mathbf{S}$ & G \\
\hline & c. Delete Data Siswa & $\sqrt{ }$ & - \\
\hline & d. Proses Data Siwa & $\sqrt{ }$ & - \\
\hline & e. Golongkan data siswa & $\sqrt{ }$ & - \\
\hline 3 & Laporan & $\sqrt{ }$ & - \\
\hline 4 & Export To Excel & $\sqrt{ }$ & - \\
\hline 5 & Halaman User My Profile & $\sqrt{ }$ & - \\
\hline 6 & $\begin{array}{l}\text { Halaman User Update } \\
\text { Profile }\end{array}$ & $\sqrt{ }$ & - \\
\hline 7 & Logout & $\sqrt{ }$ & - \\
\hline
\end{tabular}

Keterangan :

- S : Sukses

- G : Gagal

Untuk hasil pengujian yang telah dilakukan dapat diambil kesimpulan bahwa, pada setiap tampilan halaman pada aplikasi penerapan metode clustering dengan algoritma k-means pada pengelompokan data penghasilan orang tua siswa ini berjalan dengan baik dimana berupa button dan laporan semuanya berjalan dengan baik sesuai yang di harapkan pada saat proses pembuatan.

\subsection{Pengujian Browser}

Pengujian aplikasi penggunaan browser ini dilakukan dengan menggunakan dua browser. Dimana pengujian ini dilakukan untuk mengetahui tingkat keberhasilan penggunaan browser. Pada proses pengujian aplikasi penerapan metode clustering dengan algoritma k-means pada pengelompokan data penghasilan orang tua siswa ini terdapat dua browser yang digunakan yakni Mozilla Firefox versi 85 dan Chrome versi 88.0.4324.155, semuanya berjalan lancar $100 \%$ tampa terjadi kendala.

Tabel 2 Pengujian Browser

\begin{tabular}{|c|l|c|c|}
\hline No & \multicolumn{1}{|c|}{ Proses } & $\begin{array}{c}\text { Mozilla } \\
\text { Firefox }\end{array}$ & $\begin{array}{c}\text { Google } \\
\text { Chrome }\end{array}$ \\
\hline 1 & Login & $\sqrt{ }$ & $\sqrt{ }$ \\
\hline 2 & Halaman Data Siswa & $\sqrt{ }$ & $\sqrt{ }$ \\
\hline 3 & Laporan & $\sqrt{ }$ & $\sqrt{ }$ \\
\hline 4 & Export To Excel & $\sqrt{ }$ & $\sqrt{ }$ \\
\hline 5 & $\begin{array}{l}\text { Halaman User My } \\
\text { Profile }\end{array}$ & $\sqrt{ }$ & $\sqrt{ }$ \\
\hline 6 & $\begin{array}{l}\text { Halaman User Update } \\
\text { Profile }\end{array}$ & $\sqrt{ }$ & $\sqrt{ }$ \\
\hline 7 & Logout & $\sqrt{ }$ & $\sqrt{ }$ \\
\hline
\end{tabular}

Keterangan :

$\sqrt{ }:$ Berhasil

$\mathrm{X}$ : Gagal

\subsection{Pengujian User}

Pengujian user bertujuan untuk mengetahui apakah aplikasi pada penerapanya sudah berfungsi sangat baik atau tidak, untuk tahap pengujian ini ada 20 responden yakni terdapat Guru Tata Usaha dari SMK Santo Yosef Nenuk dan juga siswa. Untuk soal pertanyaan pada kuesioner ini sendiri terdapat 7 soal tentang aplikasi yang telah dibuat. Dalam menentukan hasil persentase kuesioner menggunakan rumus mencari persentase hasil kuesioner seperti berikut (Sugiyono, 2008) :

Dimana :

$$
\rho=f / n \times 100
$$

$\mathrm{p}$ : Presentase

f : Jumlah jawaban

$\mathrm{n}:$ Jumlah responden

Berdasarkan hasil dari pengisihan kuesioner yang didapatkan penulis dari responden dan dihitung jumlah keseluruhannya mendapatkan persentase hasil seperti berikut, dapat dilihat pada Tabel 3 .

Tabel 3 Pengujian User

\begin{tabular}{|c|c|c|c|c|}
\hline \multirow[b]{2}{*}{ No } & \multirow[b]{2}{*}{ Pertanyaan } & \multicolumn{3}{|c|}{ Penilaian } \\
\hline & & $\begin{array}{l}\text { Setuju } \\
\text { (S) }\end{array}$ & $\begin{array}{c}\text { Kurang } \\
\text { Setuju } \\
\text { (KS) }\end{array}$ & $\begin{array}{c}\text { Tidak } \\
\text { Setuju } \\
\text { (TS) }\end{array}$ \\
\hline 1 & $\begin{array}{l}\text { Apakah ukuran } \\
\text { dan warna font } \\
\text { tulisan sudah } \\
\text { terlihat jelas? }\end{array}$ & $\begin{array}{l}(17) \\
85 \%\end{array}$ & $\begin{array}{l}(3) \\
15 \%\end{array}$ & $\begin{array}{l}(0) \\
0 \%\end{array}$ \\
\hline 2 & $\begin{array}{l}\text { Apakah warna } \\
\text { tombol dan } \\
\text { background pada } \\
\text { aplikasi sudah } \\
\text { terlihat jelas? }\end{array}$ & $\begin{array}{l}(15) \\
75 \%\end{array}$ & $\begin{array}{c}(5) \\
25 \%\end{array}$ & $\begin{array}{l}(0) \\
0 \%\end{array}$ \\
\hline 3 & $\begin{array}{l}\text { Apakah alur } \\
\text { menu pada } \\
\text { program mudah } \\
\text { dipahami? } \\
\end{array}$ & $\begin{array}{l}(13) \\
65 \%\end{array}$ & $\begin{array}{c}(7) \\
35 \%\end{array}$ & $\begin{array}{l}(0) \\
0 \%\end{array}$ \\
\hline 4 & $\begin{array}{l}\text { Apakah form- } \\
\text { form yang ada } \\
\text { pada program } \\
\text { sudah jelas dan } \\
\text { mudah } \\
\text { digunakan? }\end{array}$ & $\begin{array}{l}(14) \\
70 \%\end{array}$ & $\begin{array}{c}(5) \\
25 \%\end{array}$ & $\begin{array}{l}(1) \\
5 \%\end{array}$ \\
\hline 5 & $\begin{array}{l}\text { Apakah kriteria } \\
\text { data yang } \\
\text { digunkan sesuai } \\
\text { dengan kriteria } \\
\text { pekerjaan orang } \\
\text { tua siswa yang } \\
\text { ada di SMK } \\
\text { Santo Yosef } \\
\text { Nenuk? }\end{array}$ & $\begin{array}{l}(16) \\
95 \%\end{array}$ & $\begin{array}{c}(4) \\
20 \%\end{array}$ & $\begin{array}{l}(0) \\
0 \%\end{array}$ \\
\hline 6 & $\begin{array}{l}\text { Apakah sistem } \\
\text { ini lebih }\end{array}$ & $\begin{array}{l}(15) \\
75 \% \\
\end{array}$ & $\begin{array}{l}5) \\
25 \%\end{array}$ & $\begin{array}{l}(0) \\
0 \% \\
\end{array}$ \\
\hline
\end{tabular}




\begin{tabular}{|c|c|c|c|c|}
\hline & $\begin{array}{l}\text { mempermudah } \\
\text { dalam } \\
\text { menentukan } \\
\text { pengelompokan } \\
\text { data siswa yang } \\
\text { membutuhkan } \\
\text { penundaan } \\
\text { pembayaran? }\end{array}$ & & & \\
\hline 7 & $\begin{array}{l}\text { Apakah sistem } \\
\text { ini lebih } \\
\text { mempercepat } \\
\text { dalam } \\
\text { menentukan } \\
\text { pengelompokan } \\
\text { data siswa yang } \\
\text { membutuhkan } \\
\text { penundaan } \\
\text { pembayaran? }\end{array}$ & $\begin{array}{l}(17) \\
85 \%\end{array}$ & $\begin{array}{c}(3) \\
15 \%\end{array}$ & $\begin{array}{l}(0) \\
0 \%\end{array}$ \\
\hline
\end{tabular}

\subsection{Pengujian metode K-means}

Pada tahap ini merupakan proses perhitungan $K$ Means pada studi kasus SMK Santo Yosep Nenuk, dalam menentukan data siswa yang membutuhkan penundaan pembayaran dengan penerapan metode clustering dengan algoritma K-means pada pengelompokan data penghasilan orang tua siswa yakni terdapat beberapa tahap sebagai berikut :

a. Pembacaan Data Training

Untuk menentukan data yang akan dianalisis dengan metode K-Means maka langkah pertama yang dilakukan adalah membaca data training. Pada kasus ini ada sejumlah 60 data training.

Tabel 4 Data Training

\begin{tabular}{|c|c|c|c|c|c|c|}
\hline No & Nis & Nama & $\begin{array}{c}\text { Kel } \\
\text { as }\end{array}$ & $\begin{array}{c}\text { Juru } \\
\text { san }\end{array}$ & $\underset{t}{\text { Alama }}$ & $\begin{array}{c}\text { Keteran } \\
\text { gan }\end{array}$ \\
\hline 1 & $\begin{array}{c}519 \\
0\end{array}$ & $\begin{array}{l}\text { Aldorianu } \\
\text { s F. Leki }\end{array}$ & XI & TKJ & $\begin{array}{l}\text { Manle } \\
\mathrm{a}\end{array}$ & $\begin{array}{l}\text { Sangat } \\
\text { Cukup }\end{array}$ \\
\hline 2 & $\begin{array}{c}520 \\
4\end{array}$ & $\begin{array}{l}\text { Arnold } \\
\text { Moruk } \\
\text { Pawarrang } \\
\text { a }\end{array}$ & XI & TKJ & Kefa & $\begin{array}{l}\text { Sangat } \\
\text { Cukup }\end{array}$ \\
\hline 3 & $\begin{array}{c}520 \\
8\end{array}$ & $\begin{array}{l}\text { Bernaldin } \\
\text { o Realino } \\
\text { Nau }\end{array}$ & XI & TKJ & $\begin{array}{l}\text { Dusun } \\
\text { Naresa } \\
\text { A }\end{array}$ & Cukup \\
\hline 4 & $\begin{array}{c}521 \\
1\end{array}$ & $\begin{array}{l}\text { Ceaser } \\
\text { M.Koloma }\end{array}$ & XI & TKJ & $\begin{array}{l}\text { Wedo } \\
\text { mu }\end{array}$ & $\begin{array}{l}\text { Sangat } \\
\text { Cukup }\end{array}$ \\
\hline 5 & $\begin{array}{c}521 \\
8\end{array}$ & \begin{tabular}{|l} 
Demetrius \\
Misa
\end{tabular} & XI & TKJ & Oenak & $\begin{array}{l}\text { Kurang } \\
\text { Cukup }\end{array}$ \\
\hline
\end{tabular}

Tabel 5 Nilai Bobot Kriteria

\begin{tabular}{|c|l|c|}
\hline \multicolumn{3}{|c|}{ Pemberian Nilai Kriteria Pekerjaan } \\
\hline No & \multicolumn{1}{|c|}{ Pekerjaan } & Nilai \\
\hline 1 & $\begin{array}{l}\text { Pegawai Negeri } \\
\text { Sipil }\end{array}$ & 5 \\
\hline
\end{tabular}

\begin{tabular}{|c|l|c|}
2 & Honorer & 10 \\
\hline 3 & Karyawan Swasta & 15 \\
\hline 4 & Buruh & 20 \\
\hline 5 & Wiraswasta & 25 \\
\hline 6 & Petani & 30 \\
\hline 7 & Ibu Rumah Tangga & 35 \\
\hline \multicolumn{3}{|c|}{ Pemberian nilai Kriteria gajih } \\
\hline No & Pendapatan & Nilai \\
\hline 1 & 0 & 50 \\
\hline 2 & Dibawah 1 Juta & 40 \\
\hline 3 & 1 Juta - 2 Juta & 30 \\
\hline 4 & 2 Juta - 3 Juta & 20 \\
\hline 5 & 3 Juta - 4 Juta & 10 \\
\hline 6 & Diatas 4 Juta & 0 \\
\hline \multicolumn{3}{|c|}{ Pemberian nilai Kriteria jumlah anak } \\
\hline No & Jumlah & Nilai \\
\hline 1 & 1 & 10 \\
\hline 2 & 2 & 20 \\
\hline 3 & 3 & 30 \\
\hline 4 & 4 & 40 \\
\hline 5 & Lebih dari 5 \\
\hline
\end{tabular}

Tabel 6 Hasil Bobot Kriteria

\begin{tabular}{|c|c|c|c|c|c|}
\hline No & K1 & K2 & K3 & K4 & K5 \\
\hline 1 & 5 & 10 & 15 & 30 & 20 \\
\hline 2 & 5 & 10 & 15 & 30 & 10 \\
\hline 3 & 25 & 20 & 35 & 50 & 10 \\
\hline 4 & 5 & 10 & 15 & 30 & 10 \\
\hline 5 & 5 & 30 & 35 & 50 & 40 \\
\hline
\end{tabular}

b. Tentukan cluster dan nilai awal centroid

Dalam proses penentuan golongan data siswa yang menerima penundaan pembayaran akan digolongkan menjadi 3 golongan yaitu kurang cukup, cukup dan sangat cukup, jadi butuhkan 3 cluster dan juga 3 centroid sebagai proses perhitungan selanjutnya. Untuk centroid awal ditentukan dengan mencari nilai tertinggi, nilai tengah dan nilai terendah pada daftar tabel. Data dilihat dari tabel bobot dengan kriteria yang dapat dilihat pada Tabel 6 .

Tabel 7 Centroid Awal

\begin{tabular}{|l|c|c|c|c|c|}
\cline { 2 - 6 } \multicolumn{1}{c|}{} & k1 & k2 & k3 & k4 & k5 \\
\hline c1 (nilai tertinggi) & 30 & 40 & 35 & 50 & 40 \\
\hline c2 (nilai tengah) & 15 & 30 & 35 & 50 & 20 \\
\hline c3 (nilai terkecil) & 5 & 10 & 5 & 20 & 10 \\
\hline
\end{tabular}

c. Perhitungan jarak data ke pusat cluster menggunakan rumus jarak Euclidean.

Pada tahap ini berfungsi mencari jarak minimum antara objek ke centroid dengan rumus Euclidean. Rumus yang digunakan yakni pada persamaan 2.1 :

$D(a, b)=\sqrt{\sum_{k=1}^{n}\left(a_{k}-b_{k}\right)^{2}} \ldots .$.

Dimana : 
a adalah data kriteria

b adalah centroid

$\mathbf{n}$ adalah jumlah data (atribut)

$\mathbf{k}$ adalah iterasi

$\boldsymbol{a}_{\boldsymbol{k}}$ dan $\boldsymbol{b}_{\boldsymbol{k}}$ adalah atribut ke-K dari objek data $\mathbf{a}$ dan $\mathbf{b}$

Iterasi ke-1 :

Hitungan data pertama centroid 1, centroid 2 dan centroid 3. Dengan menggunakan data nilai tertinggi, nilai tengah dan nilai terkecil pada tabel sebagai centroid awal dan dihitung dengan rumus Euclidean :

Jarak data dengan Centroid 1 :

$$
\begin{aligned}
& \sum_{k=1}^{n}\left(a_{k}-b_{k}\right)^{2}=(5-30)^{2}+(10-40)^{2}+(15- \\
& 35)^{2}+(30-50)^{2}+(20-40)^{2}=2725 \\
& \begin{aligned}
D(a, b) & =\sqrt{\sum_{k=1}^{n}\left(a_{k}-b_{k}\right)^{2}} \ldots \ldots \\
& =\sqrt{2725} \\
& =52,20153254
\end{aligned}
\end{aligned}
$$

Jarak data dengan Centroid 2 :

$$
\sum_{k=1}^{n}\left(a_{k}-b_{k}\right)^{2}=(5-15)^{2}+(10-30)^{2}+(15-
$$$$
35)^{2}+(30-50)^{2}+(20-20)^{2}=1300
$$$$
D(a, b)=\sqrt{\sum_{k=1}^{n}\left(a_{k}-b_{k}\right)^{2}} \ldots \ldots .
$$

$$
=\sqrt{130} 0
$$$$
=36,05551275
$$

Jarak data dengan Centroid 3 :

$\sum_{k=1}^{n}\left(a_{k}-b_{k}\right)^{2}=(5-5)^{2}+(10-10)^{2}+(15-$

$5)^{2}+(30-20)^{2}+(20-10)^{2}=300$

$$
\begin{aligned}
D(a, b)=\sqrt{\sum_{k}^{n}} & =1\left(a_{k}-b_{k}\right)^{2} \\
& =\sqrt{300} \\
& =17,32050808
\end{aligned}
$$

Hitung jarak pada setiap baris data seperti perhitungan diatas sebanyak data pada Tabel 6 , hasil perhitungan dapat dilihat pada Tabel 8.

Tabel 8 Hasil Perhitungan Jarak Data Dengan Centroid Iterasi 1

\begin{tabular}{|c|l|l|l|c|}
\hline Data Ke & \multicolumn{1}{c|}{ C-1 } & \multicolumn{1}{c|}{ C-2 } & \multicolumn{1}{|c|}{ C-3 } & $\begin{array}{c}\text { Clust } \\
\text { er }\end{array}$ \\
\hline & 52,20153 & 36,05551 & 17,32050 & \\
1 & 254 & 275 & 808 & C3 \\
\hline & 56,78908 & 37,41657 & 14,14213 & \\
2 & 346 & 387 & 562 & C3 \\
\hline & 36,40054 & 17,32050 & 47,95831 & \\
3 & 945 & 808 & 523 & C2 \\
\hline & 56,78908 & 37,41657 & 14,14213 & \\
4 & 346 & 387 & 562 & C3 \\
\hline & 26,92582 & 22,36067 & 55,67764 & \\
5 & 404 & 977 & 363 & C2 \\
\hline
\end{tabular}

Apabila sudah terdapat tabel hasil cluster untuk setiap data, proses selanjutnya mencari centroid baru untuk proses iterasi berikutnya dengan cara jumlahkan data cluster dibagi dengan jumlah anggota cluster. Hingga proses perhitungan iterasi terhenti karena nilai centroid baru pada iterasi ke-6 sama dengan nilai centroid pada iterasi ke-5 dapat dilihat pada Tabel 9.

Tabel 9 Hasil clustering

\begin{tabular}{|c|c|c|c|}
\hline Data ke-i & Cluster 1 & Cluster 2 & Cluster 3 \\
\hline 1 & & & $\sqrt{ }$ \\
\hline 2 & & & $\sqrt{ }$ \\
\hline 3 & $\sqrt{ }$ & & $\sqrt{ }$ \\
\hline 4 & & $\sqrt{ }$ & \\
\hline 5 & & $\sqrt{ }$ & \\
\hline 6 & & $\sqrt{ }$ & \\
\hline 7 & $\sqrt{ }$ & $\sqrt{ }$ & \\
\hline 8 & & & $\sqrt{ }$ \\
\hline 9 & & $\sqrt{ }$ \\
\hline 10 & & &
\end{tabular}

\section{PENGUUJIAN HASIL}

Untuk hasil cluster yang terdapat pada Tabel 9. Dilakukan pengujian dengan data training yakni sebanyak 60 data

Tabel 10 Pengujian Perhitungan K-Means

\begin{tabular}{|c|c|c|}
\hline $\begin{array}{c}\text { Data ke } \\
-n\end{array}$ & $\begin{array}{c}\text { Hasil perhitungan } \\
\text { K-Means }\end{array}$ & $\begin{array}{c}\text { Golongan Data } \\
\text { Training }\end{array}$ \\
\hline 1 & Sangat Cukup & Sangat Cukup \\
\hline 2 & Sangat Cukup & Sangat Cukup \\
\hline 3 & Kurang Cukup & Cukup \\
\hline 4 & Sangat Cukup & Sangat Cukup \\
\hline 5 & Cukup & Kurang Cukup \\
\hline
\end{tabular}

Berdasarkan Tabel 9 dapat dilihat persentase untuk pengelompokan dengan benar adalah sebesar $51 / 60 * 100 \%=85 \%$ sementara persentase untuk dimana untuk pengelompokan yang salah adalah sebesar $9 / 60 * 100 \%=15 \%$. Dimana dari 60 data siswa yang di kelompokan, terdapat 51 data siswa berhasil di clustering benar dan terdapat 9 data siswa tidak berhasil di clustering.

\section{KESIMPULAN DAN SARAN}

\subsection{Kesimpulan}

Kesimpulan yang dapat diuraikan dari hasil pembuatan sistem pengelompokan data penghasilan orang tua siswa yaitu :

1. Aplikasi pengelompokan data siswa untuk penundaan pembayaran yang dibuat dapat membantu pihak administrasi sekolah dalam menghasilkan laporan karenakan aplikasi ini sudah mamiliki fitur export to microsoft excel, yang dimana bisa melakukan export dan di cetak.

2. Dari pengujian algoritma $K$-Means dalam proses penentuan pengelompokan data siswa mampu menghasilkan tingkat akurasi dengan nilai sebesar $51 / 60 * 100 \%=85 \%$ dan tingkat eror dengan nilai 
sebesar $9 / 60 * 100 \%=15 \%$. Proses pengujian dilakukan dengan bandingkan data lama dengan data hasil clustering. Dimana dari 60 data siswa yang di kelompokan, terdapat 51 data siswa berhasil di clustering benar dan terdapat 9 data siswa tidak berhasil di clustering.

3. Pada proses hasil pengujian aplikasi yang telah dilakukan menggunakan dua browser Mozilla Firefox versi 85 dan Chrome versi 88.0.4324.155, semuanya berjalan lancar $100 \%$ tampa terjadi kendala.

\subsection{Saran}

Beberapa saran untuk pengembangan penelitian, aplikasi pengelompokan data penghasilan orang tua siswa ini sebagai berikut :

1. Pada aplikasi tersebut terdapat 5 kriteria yang dipakai, sehingga pada aplikasi ini juga bisa dikembangkan dengan penambahan kriteria.

2. Untuk aplikasi tersebut juga dapat dikembangkan dengan berbagai metode yang diinginkan metode selain K-means, diantaranya metode K-NN, metode Fuzzy C-Means dan berbagai metode lainnya yang bisa di terapkan pada aplikasi.

3. Pada aplikasi ini terdapat 3 pengelompokkan data penghasilan orang tua siswa yang terdiri dari kurang cukup, cukup dan sangat cukup. Sehingga aplikasi bisa di kembangkan untuk pengelompokkan data penghasilan orang tua siswa.

\section{DAFTAR PUSTAKA}

[1] Agusta, Yudi. "K-means-penerapan, permasalahan dan metode terkait." Jurnal Sistem dan Informatika 3.47-60 (2007).

[2] Andayani, Sri. Pembentukan cluster dalam Knowledge Discovery in Database dengan Algoritma K-Means. SEMNAS Matematika dan Pendidikan Matematika 2007 dengan tema "Trend Penelitian Matematika dan Pendidikan Matematika di Era Global, 2007.

[3] Agusta, Yudi. "K-Means-Penerapan, Permasalahan dan Metode Terkait." Jurnal Sistem dan Informatika 3.1 (2007): 47-60.

[4] Agusta, Y. (2007). K-Means-Penerapan, Permasalahan dan Metode Terkait. Jurnal Sistem dan Informatika, 3(1), 47-60.

[5] AGUSTA, Yudi. K-Means-Penerapan, Permasalahan dan Metode Terkait. Jurnal Sistem dan Informatika, 2007, 3.1: 47-60.

[6] Handoyo, R., Mangkudjaja, R., \& Nasution, S. M. (2014). Perbandingan metode clustering menggunakan metode Single Linkage dan Kmeans pada Pengelompokan Dokumen. Jurnal Sifo Mikroskil, 15(2), 73-82.

[7] Ong, Johan Oscar. "Implementasi algoritma kmeans clustering untuk menentukan strategi marketing president university." (2013).

[8] Hakim, Lukmanul.2010. Membangun Web Berbasis P HP dengan Framework Codeigniter. Yogyakarta : Lokomedia.

[9] Sibero, Alexander F.K . 2013. Web Programming Power Pack. Yogyakarta : Mediakom. 